\title{
Nilotinib-Induced Keratosis Pilaris
}

\author{
Wai Mun Sean Leong Chen Wee Derrick Aw \\ Division of Dermatology, Department of Medicine, National University Health Systems, \\ Singapore, Singapore
}

\section{Key Words}

Bcr-Abl tyrosine kinase inhibitors · Keratosis pilaris · Chronic myeloid leukaemia

\begin{abstract}
Nilotinib is a second-generation Bcr-Abl tyrosine kinase inhibitor (TKI) that is approved for the treatment of imatinib-resistant chronic myeloid leukaemia expressing the Bcr-Abl mutation. Cutaneous adverse drug reactions occur more frequently in patients using this medication. We present a case of nilotinib-induced keratosis pilaris that did not have accompanying symptoms of alopecia or pruritus. Greater recognition of this association is needed so that appropriate treatment can be instituted to ensure a good oncologic outcome.
\end{abstract}

\section{Case Report}

We report the case of a 27-year-old Indonesian Chinese male who was referred to the Dermatology unit for a non-pruritic rash on the upper and lower limbs for approximately 10 months duration. He has a significant past medical history of chronic myeloid leukaemia with a Bcr-Abl kinase mutation diagnosed 3 years ago. He was first started on imatinib 3 months after the diagnosis with a change to nilotinib 3 years later due to imatinib resistance. The patient had been receiving nilotinib $400 \mathrm{mg}$ twice a day for 3 days prior to the onset of the rash, which persisted throughout the course of nilotinib. There were no other family members with a similar rash.

On examination, the patient had extensive rough, brown, follicular papules over the trunk, upper and lower limbs (fig. 1, fig. 2). The rash was more widespread over the extensor portion of the upper limbs (fig. 3). The patient declined a skin biopsy.

\section{KARGER}


Keratosis pilaris was diagnosed and the patient was started on a topical ammonium lactate cream. Nilotinib was continued in view of the critical role of the medication in the treatment of his chronic myeloid leukaemia.

\section{Discussion}

Keratosis pilaris is a common genetic skin disorder characterised by keratinisation of the hair follicles of the skin. It is inherited in an autosomal dominant fashion, although no specific gene has been identified [1]. It typically presents as small, rough, brown folliculocentric papules distributed over characteristic areas of the skin, particularly the outer-upper arms and thighs [2]. It has been associated with ichthyosis vulgaris as well as other atopic conditions like asthma or atopic dermatitis [3]. Histologic findings include epidermal hyperkeratosis, hypergranulosis, and plugging of hair follicles. There may also be mild superficial perivascular lymphocytic changes [4]. Treatment usually involves emollients [5] and topical keratolytic agents [6].

Nilotinib is a second-generation Bcr-Abl tyrosine kinase inhibitor (TKI) that is approved for the treatment of imatinib-resistant chronic myeloid leukaemia expressing the Bcr-Abl mutation [7]. Although structurally similar to imatinib, it is approximately 10-30 times more potent than imatinib at inhibiting Bcr-Abl tyrosine kinase activity [8]. It also inhibits other kinases important in the proliferation of malignancies, e.g. Abl-Src9, which helps it overcome Bcr-resistance in cases of advanced chronic myeloid leukaemia [9]. Although these medications are generally well tolerated, cutaneous adverse drug reactions occur in approximately $34.3 \%$ of patients receiving nilotinib, with $2.6 \%$ of them exhibiting a high-grade rash [10]. Most of these reactions include dry skin, pruritus, and alopecia [11]. Notably, compared to a previous case series report, our patient did not have any pruritus nor alopecia [12]. The mechanism of these reactions are not well understood, although c-kit, which is one of the targets of TKIs, has been possibly attributed since it is not only expressed in cancer cells, but also similarly in basal skin cells and melanocytes [13]. Such reactions may influence the compliance to nilotinib therapy [14], thereby affecting the oncologic outcome.

Bcr-Abl tyrosine kinase use is increasingly common. Although it is reported to be present in approximately 23\% ( $\mathrm{n}=9$ ) of cases of adverse cutaneous reactions following such drug therapy [15], we believe greater emphasis is needed in the recognition of such an association, especially in the absence of accompanying suggestive symptoms, e.g. pruritus. Appropriate treatment should be instituted in order to increase compliance to therapy and achieve a good oncologic outcome.

\section{Statement of Ethics}

The authors have no ethical conflicts to disclose.

\section{Disclosure Statement}

The authors declare no conflicts of interest. 
Leong and Aw: Nilotinib-Induced Keratosis Pilaris

\section{References}

1 Panchaprateep R, Tanus A, Tosti A: Clinical, dermoscopic, and histopathologic features of body hair disorders. J Am Acad Dermatol 2015;72:890-900.

-2 Poskitt L, Wilkinson JD: Natural history of keratosis pilaris. Br J Dermatol 1994;130:711-713.

-3 Hwang S, Schwartz RA: Keratosis pilaris: a common follicular hyperkeratosis. Cutis 2008;82:177-180.

4 Sallakachart P, Nakjang Y: Keratosis pilaris: a clinico-histopathologic study. J Med Assoc Thai 1987;70:386389.

-5 Garwood JD: Keratosis pilaris. Am Fam Physician 1978;17:151-152.

6 Novick NL: Practical management of widespread, atypical keratosis pilaris. J Am Acad Dermatol 1984;11(2 Pt 1):305-306.

7 Jabbour E, Cortes J, Kantarjian H: Treatment selection after imatinib resistance in chronic myeloid leukemia. Target Oncol 2009;4:3-10.

8 Manley PW, Cowan-Jacob SW, Mestan J: Advances in the structural biology, design and clinical development of Bcr-Abl kinase inhibitors for the treatment of chronic myeloid leukaemia. Biochim Biophys Acta 2005;1754:3-13.

9 Musumeci F, Schenone S, Brullo C, Botta M: An update on dual Src/Abl inhibitors. Future Med Chem 2012;4:799-822.

10 Drucker AM, Wu S, Busam KJ, Berman E, Amitay-Laish I, Lacouture ME: Rash with the multitargeted kinase inhibitors nilotinib and dasatinib: meta-analysis and clinical characterization. Eur J Haematol 2013;90:142150.

11 Heidary N, Naik H, Burgin S: Chemotherapeutic agents and the skin: an update. J Am Acad Dermatol 2008;58:545-570.

$\checkmark 12$ Patel AB, Solomon AR, Mauro MJ, Ehst BD: Unique cutaneous reaction to second- and third-generation tyrosine kinase inhibitors for chronic myeloid leukemia. Dermatology 2016;232:122-125.

13 Valeyrie L, Bastuji-Garin S, Revuz J, Bachot N, Wechsler J, Berthaud P, Tulliez M, Giraudier S: Adverse cutaneous reactions to imatinib (STI571) in Philadelphia chromosome-positive leukemias: a prospective study of 54 patients. J Am Acad Dermatol 2003;48:201-206.

14 Yood MU, Oliveria SA, Cziraky M, Hirji I, Hamdan M, Davis C: Adherence to treatment with second-line therapies, dasatinib and nilotinib, in patients with chronic myeloid leukemia. Curr Med Res Opin 2012;28:213-219.

15 Delgado L, Giraudier S, Ortonne N, Zehou O, Cordonnier C, Hulin A, Chosidow O, Tulliez M, Valeyrie-Allanore L: Adverse cutaneous reactions to the new second-generation tyrosine kinase inhibitors (dasatinib, nilotinib) in chronic myeloid leukemia. J Am Acad Dermatol 2013;69:839-840. 


Case Reports in
Dermatology $\quad$\begin{tabular}{l|l}
\cline { 2 - 2 } Case Rep Dermatol 2016;8:91-96 \\
\hline DOI: 10.1159/000445676 & $\begin{array}{l}\text { ○ } 2016 \text { The Author(s). Published by S. Karger AG, Basel } \\
\text { www.karger.com/cde }\end{array}$ \\
\cline { 2 - 3 } & Leong and Aw: Nilotinib-Induced Keratosis Pilaris
\end{tabular}

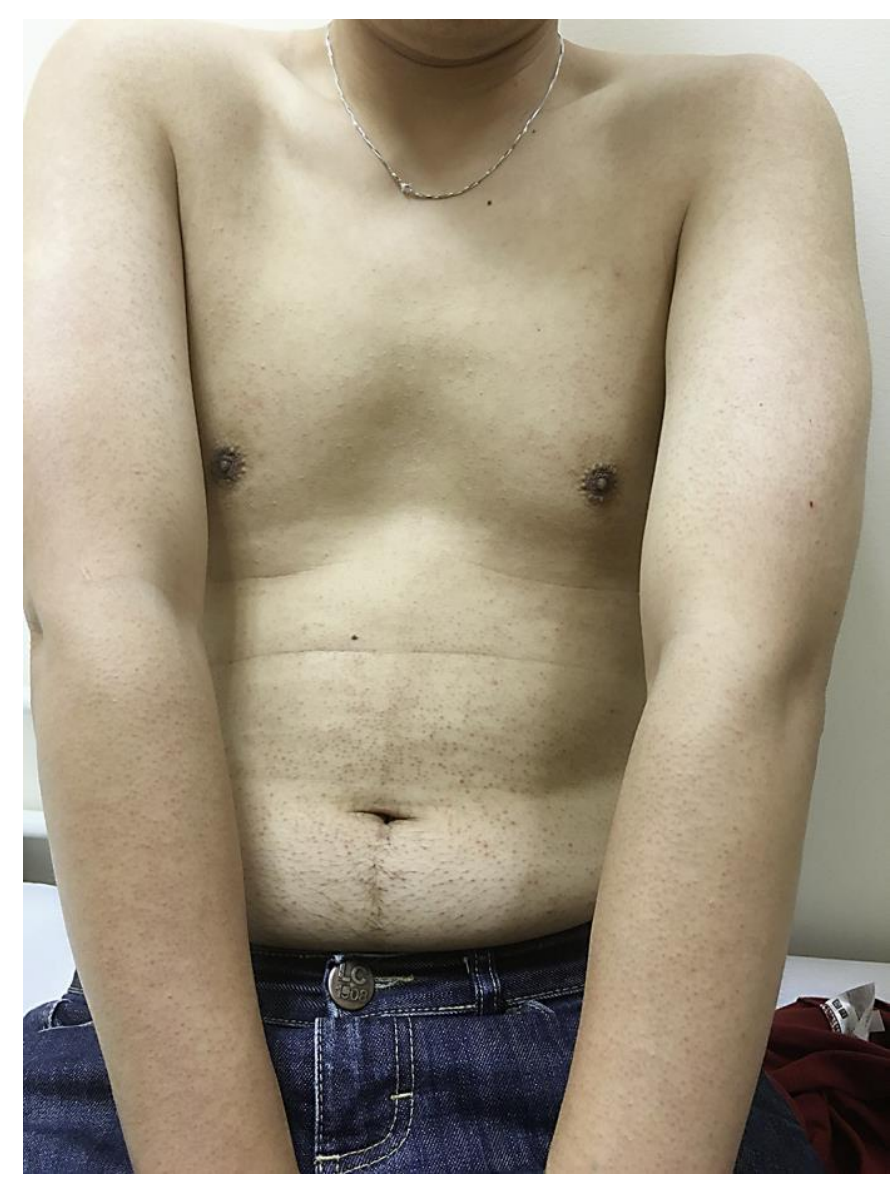

Fig. 1. Brown folliculocentric papules over the trunk and upper limbs. 


\section{Case Reports in Dermatology}

\begin{tabular}{l|l}
\hline Case Rep Dermatol 2016;8:91-96 \\
\hline DOI: 10.1159/000445676 & $\begin{array}{l}\text { (c) 2016 The Author(s). Published by S. Karger AG, Basel } \\
\text { www.karger.com/cde }\end{array}$ \\
\hline
\end{tabular}

Leong and Aw: Nilotinib-Induced Keratosis Pilaris

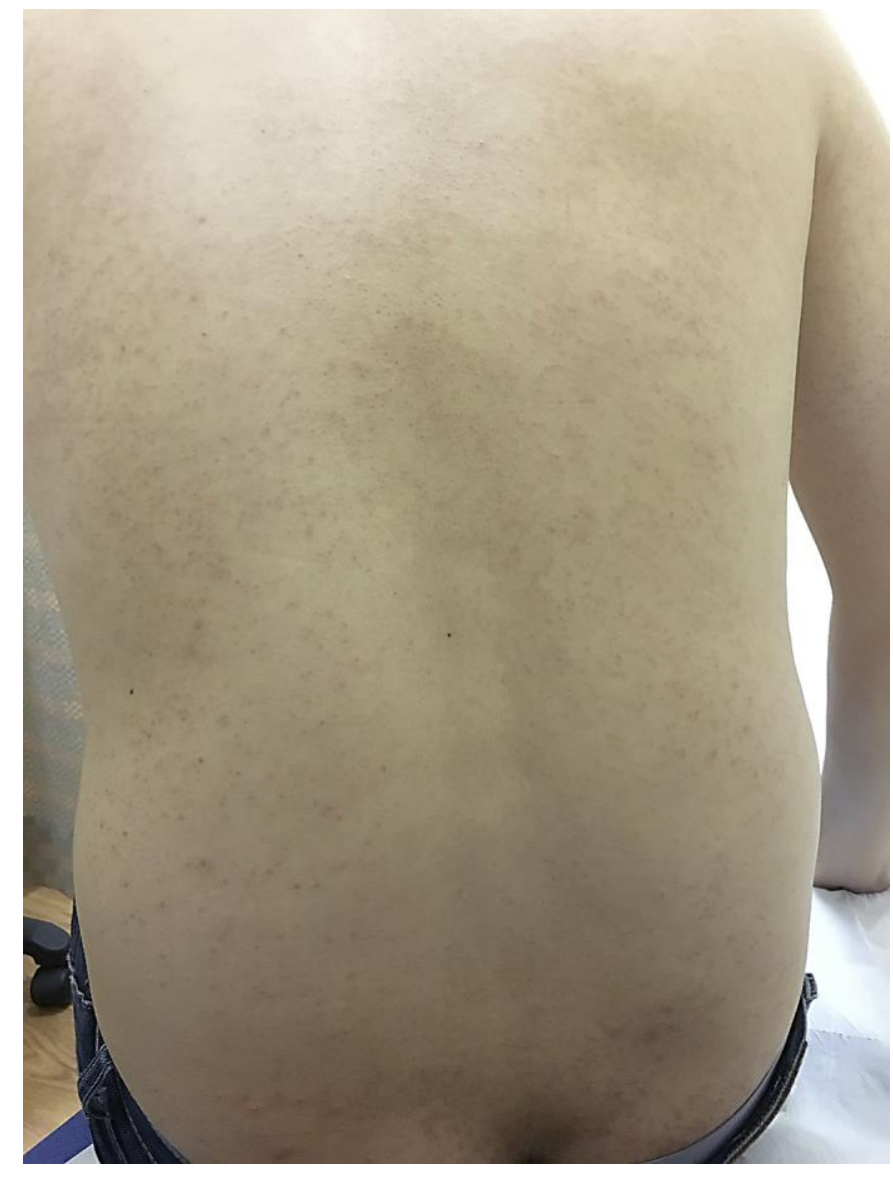

Fig. 2. Folliculocentric papules over the posterior trunk. 


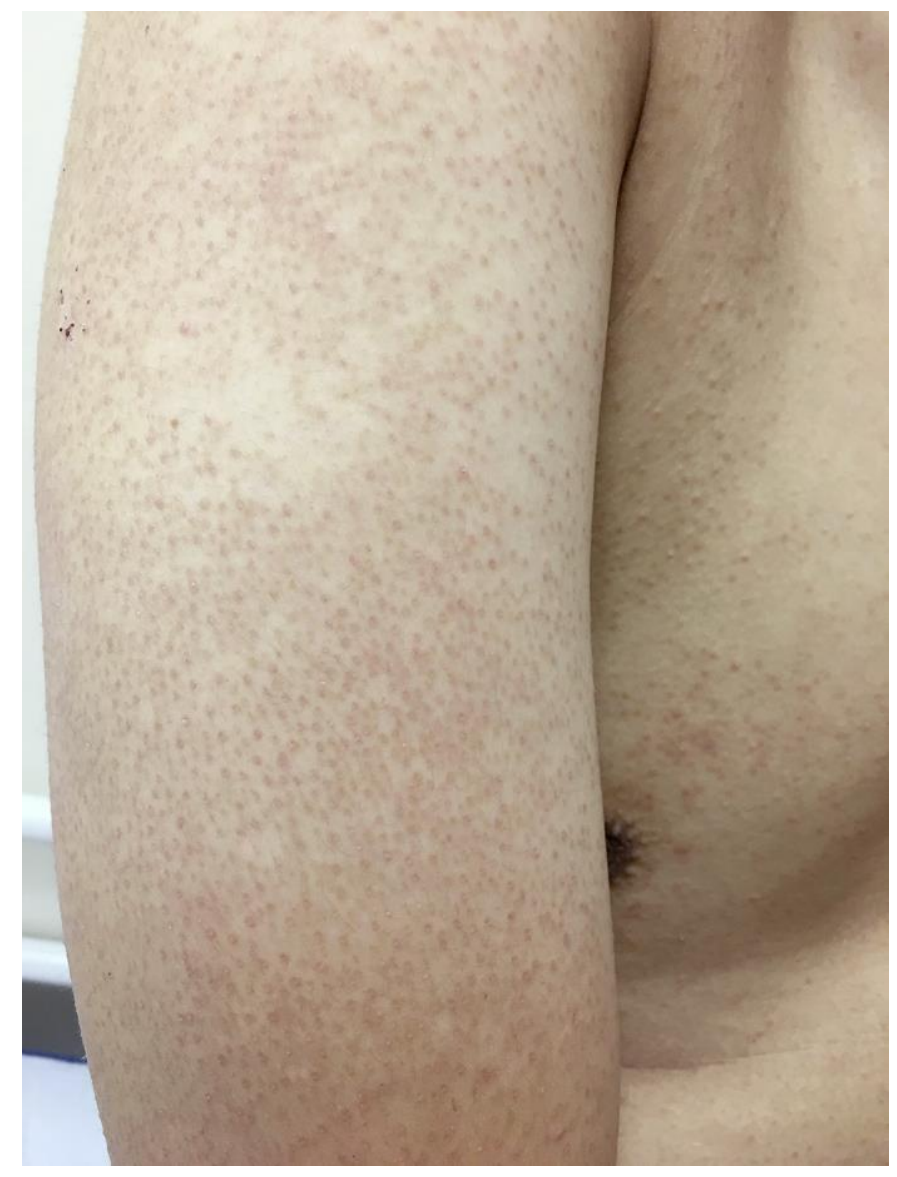

Fig. 3. Prominent papules over the posterior arm. 